\title{
Factors Associated With Marital Instability Among Rural Farming Households in Akwa Ibom State, Nigeria
}

\author{
Asa, U.A.
}

Department of Agricultural Economics and Extension, University of Uyo, Uyo, Akwa Ibom State, Nigeria

Nkan, $V . V$

Department of Human Ecology, Nutrition and Dietetics, University of Uyo, Uyo, Akwa Ibom State, Nigeria.

doi: 10.19044/esj.2017.v13n15p290 URL:http://dx.doi.org/10.19044/esj.2017.v13n15p290

\begin{abstract}
In this paper, we investigated factors associated with marital instability in rural households. Using a case study of rural farming households in Akwa Ibom State, Nigeria, we examined the demographic characteristics of married couples in rural farming households and the nature of marital instability among them in addition to ascertaining the factors associated with marital instability in the study area. Descriptive statistics and factor analysis were employed to analyze data collected from 240 married couples selected using a multi-stage sampling procedure. Results revealed that the average age of the respondents was 42 years; $91.7 \%$ of them were functionally literate; their average household size comprised of six persons; and seventeen years was their average years of marriage. Findings also revealed that majority of the respondents had low marital instability; factor analysis result showed that socio-cultural difference, psychological factor, economic factor, marriage-based factor, health factor, sex-related factor, conflict factor and communication-based factor were the major factors associated with marital instability among married persons in the study area. The findings highlight avenues of theoretical development to better understand marital instability among rural dwellers in Nigeria as well as have implications for marriage counselling among married persons in the study area.
\end{abstract}

Keywords: Marital, Instability, Rural, Farming Households, Akwa Ibom.

\section{Introduction}

Every culture of the world recognizes some form of the institution of marriage (Animasahun and Fatile, 2011). The assumption for its social 
necessity is rested on the premise that through it families are established, and family is the fundamental unit of human society (Esere, Yusuf and Omotosho, 2011). Marriage gives legitimacy to sexual relationship and reproduction for legitimate children (Omoniyi-Oyafunke, Falola and Salau, 2014), and it is linked to significant benefits in the areas of physical and mental health. These benefits stem from the economic advantages associated with the married status; from a social capital effect (the spouse provides support and helps integrate the individual into wider social networks); and from a regulative effect (marriage encourages healthy conduct partly because self-destructive behaviours impose negative externalities on the spouse) (Waite and Lehrer, 2003). The amount of gain associated with marriage varies across couples, depending on the characteristics of each partner and the quality of the match.

However, marriage and family life have undergone major changes during the past few decades globally (Musau, Kisovi and Otor, 2015); the marriage institution is witnessing instability globally (Maciver and Dimkpa, 2012). The fragility of the marriage bond is a notable feature of the contemporary world, and is present at every level of society (OmoniyiOyafunke, Falola and Salau, 2014), including rural farming households in Akwa IbomState of Nigeria. Marital instability, worrisomely, is continuously on the increase in Africa and other developing countries (Duke-Natrebo, 2014) and is associated with separation, divorce and widowhood (OmoniyiOyafunke, Falola and Salau, 2014). The increase in divorce rates is one of the most visible changes in African societies and family lives. The consequences of separation and divorce are severe (Burnam and Margolin, 1992): early experiences of parental conflict (i.e. during childhood) have lasting consequences on the quality of relationship between children and their parents (Amato and Afifi, 2006; Sobolewski and Amato, 2007); the risk of divorce or separation is high among people who experience their parents' marital instability; children from intact families have better outcomes and a higher well-being than children from divorced families (Sigle-Rushton and McLanahan, 2004); and children from divorced parents have worse cognitive, behavioural and health outcomes in general than children born into more stable families (Duke-Natrebo, 2014).

Generally, instability and the breakdown of family and conjugal ties have relevant consequences of demographic, social and economic nature for the persons involved hence the need for a deep analysis of the subject matter (Omoniyi-Oyafunke, Falola and Salau, 2014). Duke-Natrebo (2014) emphasized the importance of conducting research on marital instability and divorce in Nigeria. It is against this background that this study was conducted to investigate the factors associated with marital instability among rural farming households in Akwa Ibom, State, Nigeria. Focusing the study 
on rural farming households is germane given the economic significance of farming as the livelihood most rural dwellers in the study area are engaged in (Asa, 2008). The study also examined the demographic characteristics of married couples in the rural farming households and the nature of marital instability of the married couples as its specific objectives.

\section{Methodology}

The study was conducted in Akwa Ibom State, Nigeria. The State is wedged between Cross River, Abia and Rivers States of Nigeria; and lies between 4033" and 5033" North latitudes and 7035" and 8025" East longitudes. Akwa Ibom State of Nigeria occupies a total land area of $7,245,935 \mathrm{~km}^{2}$ and has an estimated population of 3,920,208 (National Population Commission, 2006). A multi-stage sampling procedure was used to select the respondents for the study. The first stage involved the simple random selection of four zones out of the six Agricultural Development Project (ADP) zones in Akwa IbomState, viz, Abak, Etinan,Oron and Uyo. The second stage involved the purposive selection of sixty households from rural areas in each of the four selected ADP zones. The households were purposively selected in order to ensure that only households in the rural areas of the zones were selected for the study. In the third stage of the multi-stage sampling procedure, a married couple in each of the selected households was randomly selected for the study thereby resulting in a total sample size of 240. Frequency counts, percentages and means were used to analyze the demographic characteristics of the respondents. The nature of the respondents' marital instability was measured using the Marital Instability Scale (MIS). Items in the MIS were raised based on eleven dimensions of marital stability namely: relationship/marital quality, relationship/marital conflict, intimacy, marriage and financial management, relationship/marital satisfaction, gender roles, relationship/marital support, sexual intimacy, communication, commitment and attitudes to marriage and work (Udobong, 2016). The MIS was constructed and validated by the researchers with a coefficient alpha of 0.836; its item response format was a four-point Likertscale of Strongly Agree, Agree, Disagree and Strongly Disagree which were scored with nominal values of 4,3,2 and 1 respectively for positive items while negative items were scored in reverse order. The mean of the summated scores of the MIS of the respondents (117) served as the cut-off point between low and high levels of marital instability among the respondents. Factor analysis was used to ascertain the factors associated with marital instability in the study area. 


\section{Results and Discussion}

Demographic characteristics of married couples in rural farming households: The demographic characteristics of married couples in rural farming households in Akwa Ibom State of Nigeria are shown in Table 1. The mean age of the respondents was 42 years; $69.2 \%$ of them were males while $30.8 \%$ were females. The Table reveals that majority of the respondents $(91.7 \%)$ and their spouses $(85.8 \%)$ had formal education - thus are functionally literate. Asa and Archibong (2016) also reported a high level of literacy among rural dwellers in Akwa Ibom State. Farming constituted $47.5 \%$ of the respondents' primary occupation followed by trading/business $(27.5 \%)$ and salaried jobs in the Civil Service of the Government (25.0\%). The finding corroborates Asa (2008) who reported that farming is the livelihood activity most rural dwellers in Akwa Ibom State are actively engaged in. Asa and Solomon (2010) also reported that majority of married rural dwellers in Akwa Ibom State are engaged in farming and fishing as their major income generating activities. Table 1 also reveals that majority of the respondents $(80.0 \%$ ) earned less than $\$ 40,001.00$ monthly (1 US Dollar equals 317.00 Nigerian Naira as at February 11, 2017) which shows the low level of rural household income in the study area. Asa and Solomon (2010) also reported a low level of income among rural dwellers in AkwaIbom State which agrees with the finding of this study. The average household size of the respondents comprised of six persons suggesting a relatively low household size among the respondents. Asa, Daniel and Ebong (2016) also reported that the average household size of rural dwellers in Akwa Ibom State comprised of six persons; Okoro (2004), too, stated that majority of rural dwellers in Akwa Ibom State have relatively low household sizes. Majority of the married couples $(95.8 \%)$ practice Christianity which corroborates Asa (2015) who reported that the predominant religion of rural dwellers in Akwa Ibom State is Christianity; the average years of marriage of the respondents was 17 years which is relatively high compared to the average age of the respondents ( 42 years).The respondents' average years of marriage could be attributed to the high value placed on marriage in rural areas of Akwa Ibom State which predispose rural dwellers in the study area to marry at relatively early ages (Asa, 2016).

Table 1: Demographic characteristics of married couples in rural farming households in Akwa Ibom State, Nigeria

\begin{tabular}{lllll}
\hline $\begin{array}{c}\text { Characteristics } \\
\text { Mean }\end{array}$ & Categories & Frequency & Percentage \\
\hline Age & & & \\
& 42 & $21-40$ years & 120 & 50.0 \\
& & & \\
& $41-60$ years & 100 & 41.7 \\
Sex & 61-80 years & 20 & 8.3 \\
& Male & 166 & 69.2
\end{tabular}




\begin{tabular}{llll} 
& Female & 74 & 30.8 \\
Educational status & No formal education & 20 & 8.3 \\
& Primary education & 40 & 16.7 \\
& Post-primary education & 180 & 75.0 \\
Educational status of spouse & No formal education & 34 & 14.2 \\
& Primary education & 44 & 18.3 \\
& Post-primary education & 162 & 67.5 \\
Primary occupation & Trading/business & 66 & 27.5 \\
& Civil service & 60 & 25.0 \\
Monthly income (in Naira) & Farming & 114 & 47.5 \\
& $\leq 40,000.00$ & 192 & 80.0 \\
Household size & $40,001.00-80,000.00$ & 48 & 20.0 \\
6 & $1-4$ person(s) & 80 & 33.3 \\
& & & \\
& 5-8 persons & 132 & 55.0 \\
Religion & $9-12$ persons & 28 & 11.7 \\
Years in marriage & Christianity & 230 & 95.8 \\
17 & Non-Christianity & 10 & 4.2 \\
& $1-20$ year(s) & 158 & 65.8 \\
& & & \\
& 21-40 years & 82 & 34.2 \\
\hline
\end{tabular}

Source: Field survey, 2016

Nature of marital instability among married couples in rural farming households in Akwa Ibom State: The nature of marital instability among the respondents ascertained using the mean of the summated scores of the Marital Instability Scale (MIS) isis shown in Table 2. In the Table, majority of the respondents $(62.5 \%)$ had low marital instability while $37.5 \%$ had high marital instability. This suggests a high level of marital stability among married couples in the study area which could be attributed to the high social value placed on the marriage institution in the rural areas of Akwa Ibom State which predispose married persons to strive to ensure marital instability in their marriages (Ekong, 2003). Fear of ridicule, gossip and public shaming of separated/divorced persons in the study area also serve as social control measures which compel married persons to stay married hence the high level of marital stability among the respondents as depicted in Table 2.

Table 2: Distribution of respondents based on their nature of marital instability

\begin{tabular}{lccc}
\hline Marital instability status & MIS Score & Frequency & Percentage \\
\hline Low & $<117$ & 150 & 62.5 \\
High & $\geq 117$ & 90 & 37.5 \\
Total & & 240 & 100 \\
\hline
\end{tabular}

Source: Field survey, 2016

Factors associated with marital instability in rural farming households in Akwa Ibom State: In order to ascertain the factors associated with marital instability in the study area, a set of thirty one factors were subjected 
to factor analysis using Statistical Package for the Social Sciences Version 22.0. The extraction method used in the analysis was principal components based on Eigenvalues greater than 1; and the rotation method was Varimax. The operation produced eight significant factors which accounted for $78.082 \%$ of variation in the data set as shown in Table 3. The eight significant factors - based of high loadings of the initial thirty one factors are named as follows:

1. Socio-cultural difference: This factor accounted for $15.158 \%$ of the total variation in the data set and five items highly loaded on this factor: age difference (0.812), age of marriage (0.846), religious difference (0.782), ethnic difference (0.767) and educational difference (0.809). Due to the dominance of items on differences, the factor was named socio-cultural difference. This factor is the most significant factor associated with marital instability in the study area.

2. Psychological factor: Items such as lack of confidence(0.850), desertion/abandonment (0.785), alcohol addiction (0.867), substance abuse (0.545), non-cooperating attitude (0.878) and lack of trust (0.557) loaded heavily on this factor which accounted for $14.607 \%$ of the total variation in the data set making it the second most important factor associated with marital instability in the study area.

3. Economic factor: Financial problems (0.719), joblessness (0.843) and poverty (0.864) are three items out of the thirty one original items that loaded heavily on this factor named economic factor. The factor accounted for $13.074 \%$ of the total variation in the data set.

4. Marriage-based factor: This factor accounted for $9.656 \%$ of the total variation in the data set; and items such as adultery/infidelity (0.994), non-payment of dowry (0.714), polygamy (0.665), irresponsible lifestyle (0.726) and in-laws/relatives interference (0.506) which are all marriage issues loaded heavily on this factor hence its name.

5. Health factor: Items such as barrenness/sterility (0.794), sickness/illhealth (0.790) and child preference $(0.715)$ are embedded in this factor. Health factor accounted for $8.819 \%$ of the total variation in the data set.

6. Sex-related factor: Sexual incompatibility (0.679) and sexual abuse (0.713) are the two items that loaded heavily in sex-related factor. Ambakederemo and Ganagana (2006) reported that marital instability is caused by sex-related issues, love and trust, socio-cultural factors, antisocial vices and economic factors corroborating the finding of this study.

7. Conflict factor: About $5.339 \%$ of the total variation in the data set is accounted for by conflict factor. Emotional abuse (0.613) and conflict (0.746) loaded heavily for this factor as shown in Table 3. 
8. Communication-based factor: This factor accounted for only $5.271 \%$ of the total variation in the data set making it the least important factor, out of the eight factors extracted by factor analysis in this study, associated with marital instability among married persons in the study area.

The eight factors in Table 3 agree with the works of Ezeh (2000) and Nkwocha (2002) which stated that childlessness, unsatisfactory sexual relationships, , non-payment of dowry, polygyny, rumour and faction, lack of commitment towards marriage, sexual incompatibility, infidelity, lack of communication between spouses, abandonment, alcohol addiction, substance abuse, physical abuse, sexual abuse, emotional abuse, inability to manage or resolve conflict, differences in personal and career goals, different expectations about household tasks and financial problems, intellectual incompatibility and inflexibility, mental instability or mental illness, religious beliefs, cultural and lifestyle differences are major causes of instability among couples - these were among the items that loaded heavily on the eight extracted factors.

Table 3: Rotated component matrix of factors loading for factors associated with marital instability among married couples in rural areas of Akwa Ibom State

\begin{tabular}{lllllllll}
\hline Items & & F1 & F2 & F3 & F4 & F5 & F6 & F7 \\
& F8 & & & & & & & \\
\hline
\end{tabular}

1. Adultery/infidelity

2. Barreness/sterility

3. Age difference

4. Age of marriage

5. Excessive cruelty/physical abuse

6. Religious difference

7. Ethnic difference

8. Educational difference

9. Sexual incompatibility

10. Non-payment of dowry

11. Polygamy

12. Lack of confidence

13. Communication problems 0.893

14. Desertion/abandonment

15. Alcohol addiction

16. Substance/drug abuse

17. Emotional abuse 0.613

18. Conflict

$$
0.746
$$

19. Personality differences

20. Career differences
0.994

0.794

0.812

0.846

0.782

0.767

0.809

0.714

0.665

0.850

0.785

0.867

0.545
0.679 
21. Financial problems

22. Sexual abuse

23. Intellectual incompatibility 0.623

24. Non-cooperating attitude

25. Sickness/ill-health

0.878

26. Irresponsible lifestyle

27. In-laws/relations interference

28. Joblessness

29. Poverty

30. Child preference

31. Lack of trust

Eigenvalues $1.739 \quad 1.739$

Percentage of variance $5.339 \quad 5.271$

Cumulative percentage $72.812 \quad 78.083$

\begin{tabular}{lllllll} 
& 0.878 & & & & \\
& & & & 0.790 & \\
& & & 0.726 & & \\
& & & 0.506 & & \\
& & 0.843 & & & \\
& & 0.864 & & & \\
& & & & 0.715 & \\
5.002 & 4.826 & 4.314 & 3.186 & 2.916 & 1.762 \\
15.158 & 14.607 & 13.074 & 9.656 & 8.819 & 6.159 \\
& & & & & \\
15.158 & 29.765 & 42.839 & 52.495 & 61.314 & 67.473 \\
& & & & & \\
\hline
\end{tabular}

Source: Computed from SPSS Version 22.0, 2016

\section{Conclusion and Recommendations}

The study investigated factors associated with marital instability among rural farming households in Akwa State, Nigeria. We draw two main conclusions from this study. First, even though majority of married couples in rural farming households in Akwa Ibom State have low marital instability, a significant percentage (37.5\%) still have high marital instability. This highlights the need for setting up marriage counselling clinics for partners before and after marrying, by governmental and non-governmental agencies in the study area, to help guide them on effective resolution of marital conflicts. Second, socio-cultural difference, psychological, economic and conflict were some of the factors associated with marital instability among married persons in the study area. The marriage counselling clinics recommended earlier could help address most of these factors effectively. In addition, provision of good/accessible health facilities in rural areas of the State by the Government is a necessary step to alleviating health challenges faced by married persons in the study area. towards helping married persons in the study area cope with health challenges. Health factor is a significant factor associated with marital instability in the study area.

\section{References:}

1. Amato, P. R. and Afifi, T. D. (2006) Feeling caught between parents: adult children's relations with parents and subjective well-being, Journal of Marriage and Family, 68(1): 222 - 235.

2. Ambakederemo, E. T. and Ganagana, T. (2006). Causes of marital instability in the Port Harcourt Municipality, Nigeria: Solutions and 
Counselling Implications, The Nigerian Journal of Guidance and Counselling, 11(1): $14-24$.

3. Animasahun, R. A. and Fatile, E. A. F. (2011) Patterns of marital instability among married couples in Lagos, Nigeria, Journal of African Studies and Development, 3(10): 192 - 199.

4. Asa, U. A. (2008) Livelihood activities and poverty alleviation among rural women in Akwa Ibom State, Ph.D, Department of Rural Sociology and Extension, Michael Okpara University of Agriculture, Umudike, Abia State. 157pp.

5. ......(2015) Constraints to mobile phones utilization by rural dwellers in Akwa Ibom State, Nigeria, International Journal of Information and Communication Technology Research, 5(2): 28 - 34.

6. ......(2016) Barriers to spousal communication among married couples in rural areas of Akwa Ibom State, Akwapoly Journal of Communication and Scientific Research, 1(1): 14 - 23.

7. Asa, U. A. and Archibong, E. M. (2016) Social capital and food security among rural farming households in Akwa Ibom State, Nigeria, Journal of Advances in Social-Science Humanities, 2(2): 15 -19 .

8. Asa, U. A. and Solomon, V. A. (2010) Gender participation in livelihood activities of rural dwellers in Akwa Ibom State, Nigeria, International Journal of Applied Agricultural and Apicultural Research, 6(1\& 2): $57-64$.

9. Burnam, B. and Margolin, G. (1992) Analysis of association between marital relationships and health problems, Psychological Bulletin, 112: $39-63$.

10. Duke-Natrebo, N. C. (2014)The impact of marital instability in early childhood development in Nigeria, African Education Indices, 7(1): 1 -8 .

11. Ekong, E. E. (2003) An Introduction to Rural Sociology ( $2^{\text {nd }}$ Edition), Uyo: Dove Education Publishers. pp. 341 - 395.

12. Esere, M. O., Yusuf, J. and Omotosho, J. A. (2011) Influence of spousal communication on marital instability: Implication for conducive home environment, Edo Journal of Counselling, 4(1 \&2): $50-61$.

13. Ezeh, C. A. (2002). Marital problems and their social consequences in Nigeria: The intervention rate of social work professionals. Enugu: Otuson Press.

14. Maciver, J. E. and Dimkpa, , D. I. (2012) Factors influencing marital stability, Mediterranean Journal of Social Sciences, 3(1): 437 - 442.

15. Musau, J. M., Kisovi, L. M. and Otor, S. C. J. (2015) Marital instability and its impact on female-headed household livelihoods in 
Machakos County, Kenya, International Journal of Humanities and Social Sciences, 5(8): $145-153$.

16. National Population Commission (2006) Population and Housing Census of the Federal Republic of Nigeria. Analytical Report at the National Population Commission, Abuja, Nigeria.

17. Nkwocha, C. E. (2002) Marital Relationship. Lagos: Prompt Enterprises.

18. Okoro, G. I. (2004) Perceived effect of oil spillage on the livelihood activities of women in Eastern Obolo Local Government Area of Akwa Ibom State, M.Sc., Department of Agricultural Extension and Rural Development, University of Ibadan, Ibadan. 102pp.

19. Omoniyi-Oyafunke, C., Falola, H. O. and Salau, O. P. (2014) Effect of marital instability on children in Abeokuta Metropolis, European Journal of Business and Innovation Research, 2(3): 68 - 77.

20. Sigle-Rushton, W. and McLanahan, S. (2004) Father absence and child well-being: a critical review (In) Patrick, D., Smeding, T. M. and Rainwater, L. (eds.) The Future of the Family. New York: Russell Sage Foundation.

21. Sobolewski, J. M. and Amato, P. R. (2007) Parents' discord and divorce, parent-child relationships and subjective well-being in early adulthood: Is feeling close to two parents always better than feeling close to one? Social Forces, 85(3): 1105.

22. Udobong, E. O. (2016) Factors associated with marital instability in farming households in Nsit Ibom Local Government Area, B. Agric, Department of Agricultural Economics and Extension, University of Uyo, Uyo. 45pp.

23. Waite, L. J. and Lehrer, E. (2003) Religion and Marriage: A Comparative Analysis of the ties that bind, Population and Development Review, 29: 255 - 276. 